\title{
Electromyostimulation and whole-body vibration effects in elder sarcopenic patients
}

\author{
E. Chisari ${ }^{1}$, V. Pavone ${ }^{1}$, G. Sessa ${ }^{1}$, S. Ravalli ${ }^{2}$, G. Musumeci ${ }^{2,3}$ \\ 1 Department of General Surgery and Medical Surgical Specialties, Section of Orthopedics and Traumatology, \\ AOU Policlinico-Vittorio Emanuele, University of Catania, 95100 Catania, Italy \\ 2 Department of Biomedical and Biotechnological Sciences, Human Anatomy and Histology Section, University \\ of Catania, Via S. Sofia n87, Catania, Italy \\ 3 Research Center on Motor Activities (CRAM), University of Catania, Catania 95123, Italy
}

\section{CORRESPONDING AUTHOR:}

Giuseppe Musumeci

Department of Biomedical

and Biotechnological Sciences,

Human Anatomy and Histology Section,

University of Catania,

Via S. Sofia n87, Catania, Italy

E-mail: g.musumeci@unict.it

DOI:

10.32098/mltj.03.2019.18

LEVEL OF EVIDENCE: $1 \mathrm{~A}$

\begin{abstract}
SUMMARY
Background. Sarcopenia is a progressive and generalized loss of the skeletal muscle mass and function associated to aging. Among the different possible practical approaches, the Electromyostimulation (EMS) and the whole-body vibration (WBV) were proposed. The aim of this review is to synthetize the most up-to-date evidence behind the use of this therapeutic approaches.

Methods. A systematic review and Meta-Analyses of the randomized clinical trials (RCTs) present in the literature was performed. The focus was on use of WBV and EMS in sarcopenic human subjects.

Results. Whole Body Vibration seems to be an effective alternative to other exercise and in particular resistance training in sarcopenic subjects. All the studies involved in our systematic review reported several muscle benefits, both locally and overall in the body of the patients involved. The use of WB-EMS and the consequent full body involvement is interesting and promising. In all the included RCTs several primary and secondary outcomes were evaluated: from local to overall muscle quality, size and performance, fat distribution and strength parameters

Conclusion. The EMS and WBV seems to be an effective and safe solution for sarcopenia. They should be considered in elder sarcopenic patients among the others possible approaches.
\end{abstract}

KEY WORDS

electromyostimulation; exercise; muscle loss; sarcopenia; whole-body vibration.

\section{Abbrevation}

EMS: Electromyostimulation

WBV: whole body vibration

RCTs: randomized clinical trials

PRISMA: Preferred Reporting Items for Systematic Reviews and Meta-Analyses

WB-EMS: whole body electromyostimulation

HWBV: high frequency whole body vibration

LWBV: low frequency whole body vibration

\section{BACKGROUND}

Sarcopenia, as described by the European Working Group on Sarcopenia in 2010, is a progressive and generalized loss of the skeletal muscle mass and function associated to aging (1). While in the case of muscular atrophy following disuse, the size of muscle fibers can be restored over time through physical activity, loss of muscle strength and mass following illness or sarcopenia is particularly problematic (2). The quality of muscle fibers is severely affected and usually not so easily recoverable, which is together with the performance the most significant factors in the prognosis and quality of life of these subjects $(3,4)$. In addition, sarcopenia is one the main factors in the pathogenesis and presentation of frailty syndrome $(5,6)$. Older "frail" people with sarcopenia exhibit a reduced body mass and undergo a decrease in muscle strength leading to functional dysfunction and physical disability 7 . The underlying causes of sarcopenia 
and frailty are multifactorial. Although the progressive loss of muscle mass with aging has been recognised for a long time, it is only with more recent techniques and longitudinal prospective studies that the age-related changes in body composition have begun to be described (8-11). Sarcopenia and frailty is associate with higher risk of hospitalisation $(12,13)$, a later discharge (13) and higher mortality risk (14). Although its complex pathogenesis, emerging evidence demonstrated that this process may be slowed down, interrupted, and even inverted thanks to exercise, nutritional support and active life $(2,15-17)$. While exercise training, and in particular high intensity $(\geq 70-85 \%$ of one repetition maximum) strength training, has been recommended for enhancing skeletal muscle mass quality, volume and strength in older individuals (18-20) there can be exercise prescription concerns for individuals with specific risk factors and those with comorbidities. Since these subjects may need a different training approach, several innovative possibilities were studied to better the patient's compliance. Among the different possible practical approaches, the Electromyostimulation (EMS) and the whole-body vibration (WBV) were proposed. The EMS is based on the induction of muscle contractions independently of voluntary muscle activation up to supra-maximum level. One of the evolution of EMS treatment was the possibility to apply the EMS to all body. The whole body electromyostimulation (WB-EMS) equipment enables the simultaneous activation of up to 10 regions or 14 muscle groups. The total stimulated area, up to $2600-2800 \mathrm{~cm}^{2}$, can be simultaneously activated, with selectable intensity for each region (21). The WBV is based on the tonic reflex occurring in the muscle exposed to repetitive vibrations. Reflex contraction is the result of vibration-induced small changes in muscle length (22) that leads to an increase in the activity of primary afferent endings (Ia) within the muscle spindles. The evidence for stretch reflex involvement with WBV was provided by electromyography (EMG) studies of increased neuromuscular activity during vibration both in able-bodied individuals $(22,23)$. The aim of this review is to synthetize the most up-to-date evidence behind the use of this therapeutic approaches.

\section{MATERIALS AND METHODS}

\section{Literature Search Strategy}

We conducted this systematic review according to the guidelines of the Preferred Reporting Items for Systematic Reviews and Meta-Analyses (PRISMA) (24). A systematic review of different medical electronic databases (PubMed, Science Direct, SCOPUS, Crossref and Google Schol- ar) was performed from their date of inception to the $20^{\text {th }}$ of June 2018. To achieve the maximum sensitivity of the search strategy, we combined the terms: "EMS OR WBV" with "Sarcopenia OR muscle loss" with "clinical trial" as either key words or MeSH terms. The reference lists of all retrieved articles were reviewed for further identification of potentially relevant studies and assessed using the inclusion and exclusion criteria. This study was performed according to international ethical standards (25-27).

\section{Selection criteria}

Eligible studies for the present systematic review included those dealing with the RCTs involving sarcopenic subjects and either WBV or EMS. The initial titles and abstracts screening was made using the following inclusion criteria: RCTs, written in English, published in peer review journals and dealing with the sarcopenia prevention or treatment. Exclusion criteria were articles written in other languages or studies with a focus on disuse atrophy, denervation atrophy or involving bed-constricted and neurologic patients. We also excluded all the remaining duplicates, articles dealing with other topics, involving patients with muscular degenerative diseases or without accessible abstract. Reference lists were also hand-searched for further relevant studies. All publications were limited to those involving human subjects. Abstracts, case reports, conference presentations, editorials, reviews and expert opinions were excluded.

\section{Data Extraction and Criteria Appraisal}

All data were extracted from article texts, tables and figures. All authors independently reviewed each article. Discrepancies between the authors were resolved by discussion and consensus. The final results were approved by all authors.

\section{RESULTS}

\section{Included Studies}

A total of $n=239$ articles were found. After the exclusion of duplicates $n=112$ articles were selected. At the end of the first screening, following the previously described selection criteria, we selected $n=20$ articles eligible for full text reading. Ultimately, after full text reading, and reference list check, we selected $n=17$ articles following previous written criteria. A PRISMA (24) flowchart of the method of selection and screening is provided (Figure 1). The included articles focus on WBV (25-40) and EMS (21,41-45). All the significant findings of the included articles were summarized in Table I and in Table II. 
In our study we included six studies on the use of EMS (21,41-45) involving 319 sarcopenic subjects and thirteen studies on the use of WBV (28-30,33-40) involving 865 sarcopenic subjects. The protocol of treatment for EMS studies was similar in all the studies (bipolar, 85 $\mathrm{Hz}$, impulse-width: $350 \mu$ s practising simple free weight or isometric exercises) with minor variation (time of session, $\mathrm{nr}$ of sessions per week). The WBV studies used heterogenous protocols of intervention with a focus on lower limb exercise in six studies and full body exercise in only one study.

\section{DISCUSSION}

\section{Whole Body Vibration}

Whole Body Vibration seems to be an effective alternative to other exercise and in particular resistance training in sarcopenic subjects. All the studies involved in our systematic review reported several muscle benefits, both locally and overall in the body of the patients involved. While all the other studies used the same protocol of intervention for all patients, two $(29,35,38)$ investigated low-frequency and high frequency WBV (38) and in one case an additional medium frequency (29), in different groups. In the first study, no significant treatment effect of either form of WBV was observed for any variable. However, there is evidence to support the use the high-frequency protocol. Both group subjects (particularly HWBV) exhibited significant improvement in muscle performance and strength while controls did not. LWBV subjects lost 2.1\% WB BMC and $1.4 \%$ PFA BMD during the course of the 8-mo trial (38). Importantly, the LWBV group did not lose significant bone at the hip and spine (indeed a slight increase occurred in FN area), suggesting that the vibration stimulus ameliorated the

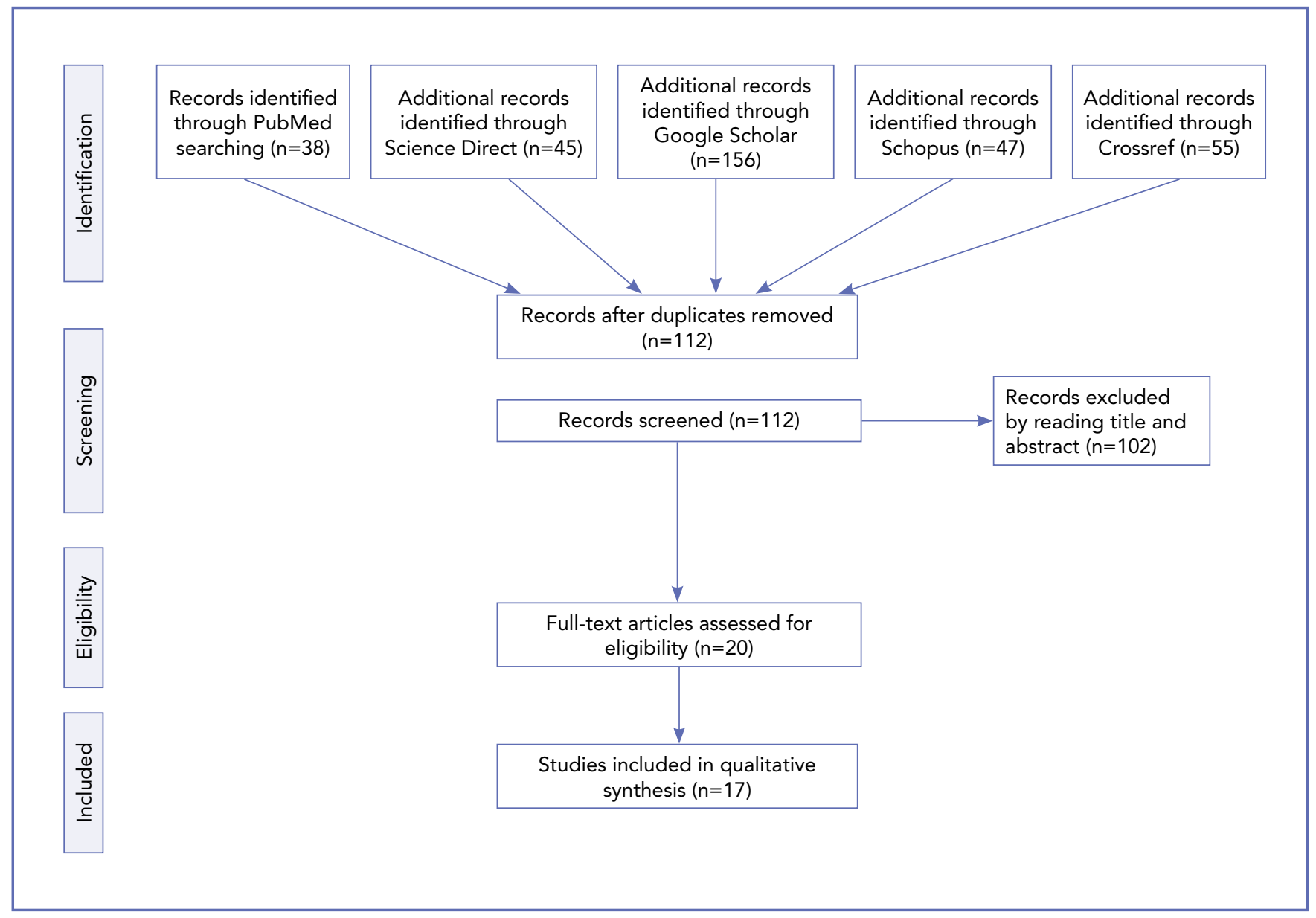

Figure 1. PRISMA (Preferred Reporting Items for Systematic Reviews and Meta-Analysis) flowchart of the systematic literature review. 
Table I. The main findings of trials involving WBV are reported.

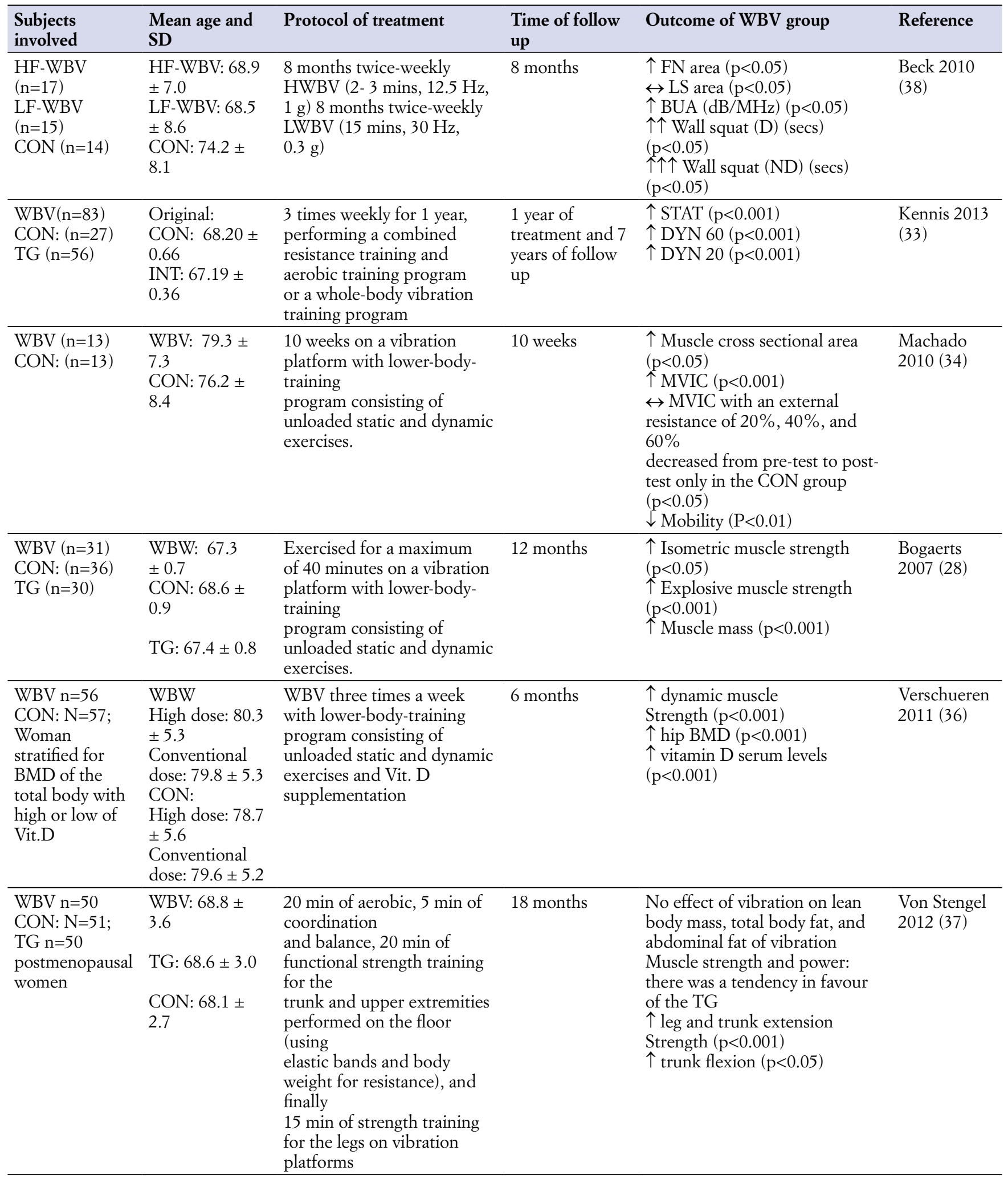




\begin{tabular}{|c|c|c|c|c|c|}
\hline $\begin{array}{l}\text { Subjects } \\
\text { involved }\end{array}$ & $\begin{array}{l}\text { Mean age and } \\
\text { SD }\end{array}$ & Protocol of treatment & $\begin{array}{l}\text { Time of follow } \\
\text { up }\end{array}$ & Outcome of WBV group & Reference \\
\hline $\begin{array}{l}\text { HF-WBV } \\
(\mathrm{n}=20) \\
\text { MF-WBV } \\
(\mathrm{n}=20) \\
\text { LF-WBV } \\
(\mathrm{n}=20) \\
\text { CON }(\mathrm{n}=20)\end{array}$ & $\begin{array}{l}\text { HF-WBV: } 74 \\
\pm 4 \\
\text { MF-WBV: } 75 \\
\pm 6 \\
\text { LF-WBV: } 78 \\
\pm 4 \\
\text { CON: } 76 \pm 6\end{array}$ & $\begin{array}{l}3 \text { days/week: } \\
\text { low-frequency long duration } \\
(20 \mathrm{~Hz} \times 720 \mathrm{~s}) \text {, medium- } \\
\text { frequency medium duration } \\
(40 \mathrm{~Hz} \times 360 \mathrm{~s}) \text {, } \\
\text { high-frequency short } \\
\text { duration }(60 \mathrm{~Hz} \times 240 \mathrm{~s}) \text { and } \\
\text { control (no training) stood } \\
\text { barefoot with } \\
\text { their knee joint flexed at } 60^{\circ} \\
\text { on the platform }\end{array}$ & $\begin{array}{l}12 \text { weeks of } \\
\text { training and } 12 \\
\text { weeks of follow } \\
\text { up }\end{array}$ & $\begin{array}{l}\uparrow \text { knee extension strength } \\
(\mathrm{p}<0.001) \\
(\text { Best in } 40 \mathrm{~Hz} \text { and } 360 \text { s group) } \\
\uparrow \text { Walking test }(\mathrm{p}<0.001) \\
\uparrow \text { Sit to stand test }(\mathrm{p}<0.001)\end{array}$ & $\begin{array}{l}\text { Wei } 2017 \\
(29,35)\end{array}$ \\
\hline $\begin{array}{l}\text { WBV }(n=17) \\
\text { CON }(n=16)\end{array}$ & $\begin{array}{l}\text { WBV: } 60.7 \pm \\
6.1 \\
\text { CON: } 61.40 \pm \\
7.30\end{array}$ & $\begin{array}{l}\text { Standing } 2 \text {-minute sessions } \\
\text { for a total of } 6 \text { minutes per } \\
\text { training session twice weekly } \\
\text { for } 6 \text { months }\end{array}$ & 6 months & $\begin{array}{l}\uparrow \text { Speed of movement }(\mathrm{p}<0.005) \\
\uparrow \text { Power }(\mathrm{p}<0.02)\end{array}$ & $\begin{array}{l}\text { Russo et al. } \\
(2003)(39)\end{array}$ \\
\hline $\begin{array}{l}\text { WBV }(n=15) \\
\text { TG }(n=15)\end{array}$ & $\begin{array}{l}\text { WBV: } 74.3 \pm \\
5.0 \\
\text { TG: } 73.1 \pm 4.1\end{array}$ & $\begin{array}{l}\text { WBV using a Galileo Sport } \\
\text { platform. The frequency } \\
\text { used for this study was set } \\
\text { at } 26 \mathrm{~Hz}, 19,23 \text { with peak-to } \\
\text { peak amplitude ranging from } \\
5 \text { to } 8 \mathrm{~mm} .3 \text { sessions per } \\
\text { week for } 8 \text { weeks }\end{array}$ & 2 months & $\uparrow$ Ankle planter flexion $(\mathrm{p}<0.01)$ & $\begin{array}{l}\text { Rees et al. } \\
(2008)(30)\end{array}$ \\
\hline $\begin{array}{l}\text { WBV }(n=13) \\
\text { CON }(n=11)\end{array}$ & $\begin{array}{l}\text { WBV: } 90.7 \pm \\
7.5 \\
\text { CON: } 83.8 \pm \\
9.3\end{array}$ & $\begin{array}{l}\text { five } 1 \text {-min vibration periods } \\
\text { with a } 1 \text {-min break between } \\
\text { each set. The IG vibrated } \\
\text { with a basic frequency } \\
\text { of } 3 \mathrm{~Hz} \text { and noise level } \\
4 \text {. To reach progressive } \\
\text { exertion, the basic frequency } \\
\text { was increased to } 6 \mathrm{~Hz} \text {, } \\
\text { depending on possibilities of } \\
\text { the individual concerned. } 3 \\
\text { days a week for } 4 \text { weeks. }\end{array}$ & 1 month & $\uparrow \operatorname{SPPB}(\mathrm{p}=0.035)$ & $\begin{array}{l}\text { Kessler et al. } \\
(2014)(33)\end{array}$ \\
\hline
\end{tabular}

WBV: whole body vibration group. CON: control group. TG: training group without vibration. PFA, proximal forearm; FN, femoral neck; HWBV, high-intensity whole body vibration; $L W B V$, low-intensity whole body vibration; $L S$, lumbar spine; BUA, broadband ultrasound attenuation; BMC, bone mineral content; $B M D$, bone mineral density; D, dominant leg; ND, nondominant leg; SLS, single leg stance; Static strength (STAT); Dynamic Strength at low speed (DYN 60); Dynamic strength at high speed (DYN 20); Maximal voluntary isometric contraction (MVIC); short physical performance battery (SPPB). Only statistically significant values were reported ( $p$ values were reported). 
Table II. The main findings of trials involving EMS are reported.

\begin{tabular}{|c|c|c|c|c|c|}
\hline Subjects involved & Mean age and SD & Protocol of treatment & $\begin{array}{l}\text { Time of } \\
\text { follow up }\end{array}$ & $\begin{array}{l}\text { Outcome of WB-EMS } \\
\text { group }\end{array}$ & Reference \\
\hline $\begin{array}{l}\text { WB-EMS }(\mathrm{n}=15) \\
\text { TG }(\mathrm{n}=15) \\
\text { postmenopausal } \\
\text { women }\end{array}$ & $\begin{array}{l}\text { WB-EMS: } 65.6 \\
\pm 5.6 \\
\text { TG: } 63.3 \pm 5.4\end{array}$ & $\begin{array}{l}2 \text { times per week 20-minute } \\
\text { WB-EMS } \\
\text { training (bipolar, } 85 \mathrm{~Hz} \text {, } \\
\text { impulse-width:350 } \mu \mathrm{s} \text { ) }\end{array}$ & 14 weeks & $\begin{array}{l}\uparrow \text { MIS-leg }(\mathrm{p}<0.001) \\
\downarrow \mathrm{WC}(\mathrm{p}<0.001)\end{array}$ & $\begin{array}{l}\text { Kemmler } \\
2010(41)\end{array}$ \\
\hline $\begin{array}{l}\text { WB-EMS }(\mathrm{n}=38) \\
\text { TG }(\mathrm{n}=38) \\
\text { lean, non-sportive } \\
\text { women }\end{array}$ & $\begin{array}{l}\text { WB-EMS: } 74.7 \\
\pm 3.7 \\
\text { TG: } 74.7 \pm 4.4\end{array}$ & $\begin{array}{l}18 \text { min of WB-EMS (bipolar, } 85 \\
\mathrm{~Hz}) 3 \text { sessions in } 14 \text { days (1.5 } \\
\text { sessions/week) }\end{array}$ & 12-months & $\begin{array}{l}\uparrow \text { ASMM }(\mathrm{p}<0.05) \\
\uparrow \text { LBM }(\mathrm{p}<0.05) \\
\uparrow \text { MIS-leg }(\mathrm{p}<0.001) \\
\uparrow \text { MIS-trunk }(\mathrm{p}<0.001)\end{array}$ & $\begin{array}{l}\text { Kemmler } \\
2014(43)\end{array}$ \\
\hline $\begin{array}{l}\text { WB-EMS }(\mathrm{n}=23) \\
\text { TG }(\mathrm{n}=23) \\
\text { lean, non-sportive } \\
\text { women }\end{array}$ & $\begin{array}{l}\text { WB-EMS: } 74.7 \\
\pm 3.9 \\
\text { TG: } 74.7 \pm 3.9\end{array}$ & $\begin{array}{l}18 \text { minutes of intermittent, } \\
\text { bipolar WB-EMS }(85 \mathrm{~Hz}) 3 \\
\text { sessions in } 14 \text { days }\end{array}$ & 12 months & $\begin{array}{l}\uparrow \text { ASMM }(\mathrm{p}<0.05) \\
\uparrow \text { MIS-leg }(\mathrm{p}<0.05)\end{array}$ & $\begin{array}{l}\text { Kemmler } \\
2013(42)\end{array}$ \\
\hline $\begin{array}{l}\text { WB-EMS\&P }(\mathrm{n}= \\
\text { 21) } \\
\text { WB-EMS ( } \mathrm{n}=24) \\
\text { NT }(\mathrm{n}=22) \\
\text { women } \geq 70 \text { with } \\
\text { sarcopenic obesity }\end{array}$ & $\begin{array}{l}\text { WB-EMS\&P: } \\
76.4 \pm 2.9 \\
\text { WB-EMS: } \\
77.3 \pm 4.9 \\
\text { NT: } 77.4 \pm 4.9\end{array}$ & $\begin{array}{l}\text { WB-EMS program in a supine } \\
\text { sitting/lying position } \\
\text { with slight movements (e.g., leg } \\
\text { and arm flexion and } \\
\text { extension during the impulse } \\
\text { phase) of the lower and upper } \\
\text { limbs once a week. (bipolar, } \\
85 \mathrm{~Hz} \text {, impulse-width: } 350 \mu \mathrm{s} \text { ) } \\
\text { intermittently with } 4-6 \mathrm{~s} \text { of } \\
\text { EMS simulation using a direct } \\
\text { impulse } \\
\text { boost and } 4 \mathrm{~s} \text { of rest. The length } \\
\text { of the session was progressively } \\
\text { increased up to } 20 \text { min after } 8 \\
\text { weeks. }\end{array}$ & 6 months & $\begin{array}{l}\downarrow \text { Sarc-Z-score }(\mathrm{p}<0.001) \\
\uparrow \mathrm{SMI}(\mathrm{p}<0.001)\end{array}$ & $\begin{array}{l}\text { Kemmler } \\
2016 \\
\text { FORMOsA } \\
\text { study (44) }\end{array}$ \\
\hline $\begin{array}{l}\text { WB-EMS\&P } \\
(\mathrm{n}=33) \\
\text { CON }(\mathrm{n}=34) \\
\text { Sarcopenic and } \\
\text { obese Bavarian } \\
\text { men } \geq 70 \text { years }\end{array}$ & $\begin{array}{l}\text { WB-EMS\&P: } \\
77.1 \pm 4.3 \\
\text { CON: } 76.9 \pm 5.1\end{array}$ & $\begin{array}{l}\text { WB-EMS standard protocol } \\
\text { (bipolar, } 85 \mathrm{~Hz} \text {, impulse- } \\
\text { width:350 } \mu \text { s) in a standing } \\
\text { position } 1.5 \times 20 \text { min } 3 \text { per week }\end{array}$ & 16 weeks & $\begin{array}{l}\uparrow \operatorname{ASMM}(\mathrm{p}<0.001) \\
\downarrow \mathrm{TBF}(\mathrm{p}<0.001) \\
\downarrow \mathrm{TF}(\mathrm{p}<0.001) \\
\uparrow \mathrm{MV}(\mathrm{p}<0.001) \\
\leftrightarrow \operatorname{IMF}(\mathrm{p}<0.001) \\
\uparrow \uparrow \mathrm{MDS}(\mathrm{p}<0.001) \\
\leftrightarrow \operatorname{HGV}(\mathrm{p}<0.001)\end{array}$ & $\begin{array}{l}\text { Kemmler } \\
\text { FranSO } \\
\text { study }(21,45)\end{array}$ \\
\hline
\end{tabular}

WB- EMS: whole body electromyostimulation group. CON: control group. TG: training group without vibration. Whey protein supplementation group (WPS). Whole body electromyostimulation and protein group (WB-EMSEP). No training group (NT).

Appendicular skeletal muscle mass (ASMM); Lean body mass (LBM); Maximum isometric leg (MIS-leg) and trunk strength (MIS-trunk). total body fat mass (TBF); trunk fat mass (TF); fat-free intra-fascial muscle volume (MV) and intra-fascial fat (IMF) of the mid-thigh; maximum dynamic strength (peak torque) of the leg and hip extensors (MDS); habitual gait velocity (HGV); waist circumference (WC); skeletal muscle mass index (SMI: ASMM/body height 2; measured in $\mathrm{kg} / \mathrm{m} 2$ ); sarcopenia Z-score (sarc-Z-score). Only statistically significant values were reported (p values are reported).

effects of systemic bone loss at sites most directly exposed to the stimulus (38). The results were not definitive. In the second study, the combination of $40 \mathrm{~Hz}$ and $360 \mathrm{~s}$ of WBV exercise had the best outcome among all other combinations tested. In order to clear out the role of the frequency of WBV we highly encourage further RCTs with different frequency protocols. In all the study, there is evidence of a gain in isometric and dynamic strength in all the subject treated which is a key factor in the quality of life of these patients $(2,3)$.

However, out of seven study included in these articles only three studies involved a training group in addition to the control not active group. While, in one meta-analysis by Osawa and Oguma (46) it was reported a significant increase 
in muscle strength in the whole body vibration group compared to control, it has been show how resistance training facilitated greater improvements in muscle strength than other interventions and WBV itself (47). For this reason, the body composition modification, with a special focus on muscle performance should be studied together with a resistance training group. In addition, while whole-body vibration may give small improvements in physical performance in older people, there are some practical considerations. Standing on the vibration system is most effective and easier for older people who are unable to follow instructions and thus find it difficult to perhaps complete other forms of exercises. Nevertheless, the price of a vibration machine may be prohibitive for some people.

\section{Whole Body Electromyostimulation}

The use of WB-EMS and the consequent full body involvement is interesting and promising. In all the included RCTs several primary and secondary outcomes were evaluated: from local to overall muscle quality, size and performance, fat distribution and strength parameters. The WB-EMS seems to both affect muscle parameters, which was to be expected, and abdominal body fat, which is a one of main risk factors in metabolic syndrome (48). Although the exercise volume was low (twice a week 20 minutes to 3 times a week $20 \mathrm{~min}$ ) and the patients were older than 60 years in all the studies, WB-EMS with its simultaneous stimulation of $2,650 \mathrm{~cm}$ of total area along with the subsequent adaptive response may trigger the corresponding effect. However, the author in one study (42) also used an indirect calorimetry to investigate the energy expenditure without reporting a result high enough (412 $\pm 61 \mathrm{kcal} / \mathrm{hour})$ to explain the corresponding abdominal fat mass changes (49). However, this may be due to the not-detectable extra-mitochondrial fraction of energy with this method, so metabolic effect of WB-EMS is still not clearly known. The effects on appendicular muscle mass in the Test-III trial $(42,43)$, and in FranSO study were comparable to the lean body mass changes with conventional resistance exercise $(50,51)$, at least with respect to the elderly subgroup of this aging adult cohort. Thus, with an adequate protocol of exercise, followed for at least 6 months and a high patients compliance, WB-EMS seems a good alternative to resistance-training in old sarcopenic subjects. In addition, in the FORMOsA and FranSO studies conducted by Kemmler et al. $(19,44,45)$ WB-EMS effects on obese patients were evaluated. While the muscle effects were similar to those involving normal weight subjects, the intervention showed also some changes in energetic metabolism affecting fat presence in the body. Even though both the WB-EMS and WB-EMS\&P group showed favourably effects on body composition and lean MV, the study failed to show any relevant change of intra-fascial fat content of the mid-thigh in the group with a protein supplementation. Although a possible reason behind this result may be related to the short follow up in the case of FranSO study (16wks), similar results were reported in FORMOsA study (6 months). Basing on these data, we can conclude that the longer follow-up was not enough to get a better result although in the FORMOsA study, the intervention was significantly different and low-demanding compared to the other studies. What emerged is that the physical activity duration and the protocol of exercise used were more significant than macronutrients split changes.

There are some limitations in our analyses e.g the great heterogeneity of primary and secondary outcome of both WBV and EMS studies did not allow a comparative statistical analysis, several points come out after reviewing the previously enlisted RCTs. These conclusions may be limited by the absence of the criteria to do a metanalysis of the studies involved in the review. While our analysis is clinically relevant, to achieve a better analysis of the present and future results, we highly encourage a standardization of both EMS and WBV based on the recent literature available and on our study. In addition, the current literature on WB-EMS is based on the numerous work made by Kemmler et al. during the last 10 years. Moreover, vibration therapy has been proposed as an option to improve physical performance and reduce the negative effects of ageing on bone, cartilage, muscles and tendons (52). Several discrepancies exist on the type of applications, frequency and magnitude (53). These differences reflex on the contradictory clinical results in the literature for the clinical applications of vibration therapy and exercise in orthopaedic practice (54-56).

\section{CONCLUSION}

Both WBV and EMS seems to be effective as alternative to resistance training in elder sarcopenic people. In addition, these low demand activities, seems to augment the subject's compliance thanks to a high accessibility. What emerged by this review is that both WBV are safe and effective therapeutic approach for Sarcopenia in elder patients. Their use should be considered among the different clinical solutions. While both treatments seem to have also metabolic effect and could be used safely in elder obese subjects, further RCTs are needed to standardize the protocol and confirm the previously reported RCTs clinical outcomes. 


\section{Acknowledgements}

This study was supported by the University Research Project Grant (Triennial Research Plan 2016-2018), Department of Biomedical and Biotechnological Sciences (BIOMETEC), University of Catania, Italy and by IFASS SWISS SA, Chiasso, Switzerland.

\section{Conflict of interest}

The Authors declare that they do not have any conflict of interest.

\section{REFERENCES}

1. Cruz-Jentoft, A. J. et al. Sarcopenia: European consensus on definition and diagnosis. Age Ageing 39, 412-423 (2010).

2. Musumeci, G. et al. Somitogenesis: From somite to skeletal muscle. Acta Histochem 117, 313-28 (2015).

3. Musumeci, G. Sarcopenia and Exercise "The State of the Art". J. Funct. Morphol. Kinesiol. 2, 40 (2017).

4. Forman, D. E. et al. Prioritizing Functional Capacity as a Principal End Point for Therapies Oriented to Older Adults with Cardiovascular Disease: A Scientific Statement for Healthcare Professionals from the American Heart Association. Circulation 135, e894-e918 (2017).

5. Fried, L. P. et al. Frailty in Older Adults: Evidence for a Phenotype. Journals Gerontol. Ser. A Biol. Sci. Med. Sci. 56, M146M157 (2001).

6. Bauer, J. M. \& Sieber, C. C. Sarcopenia and frailty: A clinician's controversial point of view. Experimental Gerontology 43, 674-678 (2008).

7. Forrest, K. Y. Z., Zmuda, J. M. \& Cauley, J. A. Patterns and determinants of muscle strength change with aging in older men. Aging Male 8, 151-156 (2005).

8. Delmonico, M. J. et al. Longitudinal study of muscle strength, quality, and adipose tissue infiltration. Am. J. Clin. Nutr. 90, 1579-1585 (2009).

9. Fantin, F. et al. Longitudinal body composition changes in old men and women: Interrelationships with worsening disability. Journals Gerontol. - Ser. A Biol. Sci. Med. Sci. 62, 1375-1381 (2007)

10. Frontera, W. R. et al. Muscle fiber size and function in elderly humans: a longitudinal study. J. Appl. Physiol. 105, 637-642 (2008).

11. Song, M. Y. et al. Sarcopenia and increased adipose tissue infiltration of muscle in elderly African American women. Am. J. Clin. Nutr. 79, 874-880 (2004).

12. Cawthon, P. M. et al. Do muscle mass, muscle density, strength, and physical function similarly influence risk of hospitalization in older adults? J. Am. Geriatr. Soc. 57, 1411-1419 (2009).

13. Van Ancum, J. M. et al. Change in muscle strength and muscle mass in older hospitalized patients: A systematic review and meta-analysis. Exp. Gerontol. 92, 34-41 (2017).

14. Beaudart, C., Zaaria, M., Pasleau, F., Reginster, J.-Y. \& Bruyère, O. Health Outcomes of Sarcopenia: A Systematic Review and Meta-Analysis. PLoS One 12, e0169548 (2017).
15. Rivas, D. A. \& Fielding, R. A. Exercise as a countermeasure for sarcopenia. in Sarcopenia - Age-Related Muscle Wasting and Weakness: Mechanisms and Treatments 333-371 (Springer Netherlands, 2011). doi:10.1007/978-90-481-9713-2_15

16. Koopman, R., Verdijk, L. B. \& Van Loon, L. J. C. Exercise and nutritional interventions to combat age-related muscle loss. in Sarcopenia - Age-Related Muscle Wasting and Weakness: Mechanisms and Treatments 289-315 (Springer Netherlands, 2011). doi:10.1007/978-90-481-9713-2_13

17. Beaudart, C. et al. Nutrition and physical activity in the prevention and treatment of sarcopenia: systematic review. Osteoporosis International 28, 1817-1833 (2017).

18. Borde, R., Hortobágyi, T. \& Granacher, U. Dose-Response Relationships of Resistance Training in Healthy Old Adults: A Systematic Review and Meta-Analysis. Sports Medicine 45, 1693-1720 (2015).

19. Garber, C. E. et al. Quantity and quality of exercise for developing and maintaining cardiorespiratory, musculoskeletal, and neuromotor fitness in apparently healthy adults: Guidance for prescribing exercise. Med. Sci. Sports Exerc. 43, 1334-1359 (2011).

20. Baker, B. \& A., B. Efficacy of Age-Specific High-Intensity Stretch-Shortening Contractions in Reversing Dynapenia, Sarcopenia, and Loss of Skeletal Muscle Quality. J. Funct. Morphol. Kinesiol. 3, 36 (2018).

21. Kemmler, W., Kohl, M., Freiberger, E., Sieber, C. \& Von Stengel, S. Effect of whole-body electromyostimulation and / or protein supplementation on obesity and cardiometabolic risk in older men with sarcopenic obesity: The randomized controlled FranSO trial. BMC Geriatr. (2018). doi:10.1186/ s12877-018-0759-6

22. Cochrane, D. J., Loram, I. D., Stannard, S. R. \& Rittweger, J. Changes in joint angle, muscle-tendon complex length, muscle contractile tissue displacement, and modulation of EMG activity during acute whole-body vibration. Muscle and Nerve 40, 420-429 (2009).

23. Abercromby, A. F. J. et al. Variation in neuromuscular responses during acute whole-body vibration exercise. Med. Sci. Sports Exerc. 39, 1642-1650 (2007).

24. Moher, D., Liberati, A., Tetzlaff, J., Altman, D. G. \& PRISMA Group. Preferred Reporting Items for Systematic Reviews and Meta-Analyses: The PRISMA Statement. PLoS Med. 6, e1000097 (2009).

25. Castorina, S. et al. Clinical evidence of traditional vs fast track recovery methodologies after total arthroplasty for osteoarthritic knee treatment. A retrospective observational study. Muscles. Ligaments Tendons J. 7, 504-513 (2017).

26. Guglielmino, C. et al. Single and dual incision technique for acute distal biceps rupture: Clinical and functional outcomes. Muscles. Ligaments Tendons J. 6, 453-460 (2016).

27. Padulo, J., Oliva, F., Frizziero, A. \& Maffulli, N. Muscles, ligaments and tendons journal - Basic principles and recommendations in clinical and field science research: 2016 update. Muscles. Ligaments Tendons J. 6, 1-5 (2016).

28. Bogaerts, A. et al. Impact of Whole-Body Vibration Training Versus Fitness Training on Muscle Strength and Muscle Mass in Older Men: A 1-Year Randomized Controlled Trial. Journals Gerontol. Ser. A Biol. Sci. Med. Sci. 62, 630-635 (2007).

29. Wei, N., Pang, M. Y. C., Ng, S. S. M. \& Ng, G. Y. F. Optimal frequency/time combination of whole-body vibration training 
for improving muscle size and strength of people with age-related muscle loss (sarcopenia): A randomized controlled trial. Geriatr. Gerontol. Int. 17, 1412-1420 (2017).

30. Rees, S. S., Murphy, A. J. \& Watsford, M. L. Effects of WholeBody Vibration Exercise on Lower-Extremity Muscle Strength and Power in an Older Population: A Randomized Clinical Trial. Phys. Ther. 88, 462-470 (2008).

31. Fjeldstad, C., Palmer, I. J., Bemben, M. G. \& Bemben, D. A. Maturitas Whole-body vibration augments resistance training effects on body composition in postmenopausal women. 63, 79-83 (2009)

32. Kessler, J., Radlinger, L., Baur, H. \& Rogan, S. Effect of stochastic resonance whole body vibration on functional performance in the frail elderly: A pilot study. Arch. Gerontol. Geriatr. 59, 305-311 (2013).

33. Kennis, E. et al. Long-term impact of strength training on muscle strength characteristics in older adults. Arch. Phys. Med. Rebabil. 94, 2054-2060 (2013).

34. Machado, A., García-López, D., González-Gallego, J. \& Garatachea, N. Whole-body vibration training increases muscle strength and mass in older women: A randomized-controlled trial. Scand. J. Med. Sci. Sport. 20, 200-207 (2010).

35. Wei, N., Pang, M. Y. C., Ng, S. S. M. \& Ng, G. Y. F. Optimal frequency/time combination of whole body vibration training for developing physical performance of people with sarcopenia: A randomized controlled trial. Clin. Rebabil. 31, 13131321 (2017).

36. Verschueren, S. M. et al. The effects of whole-body vibration training and vitamin D supplementation on muscle strength, muscle mass, and bone density in institutionalized elderly women: A 6-month randomized, controlled trial. J. Bone Miner. Res. 26, 42-49 (2011).

37. von Stengel, S., Kemmler, W., Engelke, K. \& Kalender, W. A. Effect of whole-body vibration on neuromuscular performance and body composition for females 65 years and older: A randomized-controlled trial. Scand. J. Med. Sci. Sport. 22, 119-127 (2012).

38. Beck, B. R. \& Norling, T. L. The Effect of 8 Months of Twice-Weekly Low- or Higher Intensity Whole Body Vibration on Risk Factors for Postmenopausal Hip Fracture. Am. J. Phys. Med. Rebabil. 89, 997-1009 (2010).

39. Russo, C. R. et al. High-Frequency Vibration Training Increases Muscle Power in Postmenopausal Women. Arch. Phys. Med. Rebabil. 84, 1854-1857 (2003).

40. Rees, S., Murphy, A. \& Watsford, M. Effects of vibration exercise on muscle performance and mobility in an older population. J. Aging Phys. Act. 15, 367-381 (2007).

41. Kemmler, W., Schliffka, R., Mayhew, J. L. \& Von Stengel, S. Effects of whole-body electromyostimulation on resting metabolic rate, body composition, and maximum strength in postmenopausal women: The training and electrostimulation trial. J. Strength Cond. Res. 24, 1880-1887 (2010).

42. Kemmler, W. \& von Stengel, S. Whole-body electromyostimulation as a means to impact muscle mass and abdominal body fat in lean, sedentary, older female adults: Subanalysis of the TEST-III trial. Clin. Interv. Aging 8, 1353-1364 (2013).
43. Kemmler, W., Bebenek, M., Engelke, K. \& Von Stengel, S. Impact of whole-body electromyostimulation on body composition in elderly women at risk for sarcopenia: The Training and ElectroStimulation Trial (TEST-III). Age (Omaba). 36, 395-406 (2014).

44. Kemmler, W. et al. Whole-body electromyostimulation to fight sarcopenic obesity in community-dwelling older women at risk. Resultsof the randomized controlled FORMOsA-sarcopenic obesity study. Osteoporos. Int. 27, 3261-3270 (2016).

45. Kemmler, W., Grimm, A., Bebenek, M., Kohl, M. \& von Stengel, S. Effects of Combined Whole-Body Electromyostimulation and Protein Supplementation on Local and Overall Muscle/Fat Distribution in Older Men with Sarcopenic Obesity: The Randomized Controlled Franconia Sarcopenic Obesity (FranSO) Study. Calcif. Tissue Int. 0, 1-12 (2018).

46. Osawa, Y. \& Oguma, Y. Effects of resistance training with whole-body vibration on muscle fitness in untrained adults. Scand. J. Med. Sci. Sports 23, 84-95 (2013).

47. Lai, C.-C., Tu, Y.-K., Wang, T.-G., Huang, Y.-T. \& Chien, K.-L. Effects of resistance training, endurance training and whole-body vibration on lean body mass, muscle strength and physical performance in older people: a systematic review and network meta-analysis. Age Ageing 47, 367-373 (2018).

48. Alberti, K. G. M. M., Zimmet, P. \& Shaw, J. Metabolic syndrome - A new world-wide definition. A consensus statement from the International Diabetes Federation. Diabetic Medicine 23, 469-480 (2006).

49. Kemmler, W., Von Stengel, S., Schwarz, J. \& Mayhew, J. L. Effect of whole-body electromyostimulation on energy expenditure during exercise. J. Strength Cond. Res. 26, 240-245 (2012).

50. Kemmler, W., von Stengel, S., Engelke, K., Häberle, L. \& Kalender, W. A. Exercise Effects on Bone Mineral Density, Falls, Coronary Risk Factors, and Health Care Costs in Older Women. Arch. Intern. Med. 170, 179 (2010).

51. Peterson, M. D., Sen, A. \& Gordon, P. M. Influence of resistance exercise on lean body mass in aging adults: A meta-analysis. Med. Sci. Sports Exerc. 43, 249-258 (2011).

52. Musumeci, G. The Use of Vibration as Physical Exercise and Therapy. J. Funct. Morphol. Kinesiol. 2, 17 (2017).

53. Cerciello, S., Rossi, S., Visonà, E., Corona, K., Oliva, F. Clinical applications of vibration therapy in orthopaedic practice. Muscles. Ligaments. Tendons. J. 6, 147-156 (2016).

54. Musumeci, G. et al. Advantages of exercise in rehabilitation, treatment and prevention of altered morphological features in knee osteoarthritis. A narrative review. Histol. Histopathol. 29, 707-719 (2014).

55. Musumeci G. Effects of exercise on physical limitations and fatigue in rheumatic diseases. World J Orthop. 2015 Nov 18;6(10):762-9.

56. 56. Castrogiovanni P, Trovato FM, Szychlinska MA, Nsir H, Imbesi R, Musumeci G. The importance of physical activity in osteoporosis. From the molecular pathways to the clinical evidence. Histol Histopathol. 2016 Nov;31(11):1183-94. 